\title{
Gem Trade LAB NOTES
}

\section{CORUNDUM, More on Heat Treatment}

We have been told that conservative gem traders in Sri Lanka have been reluctant to start heat treating their own "geuda" corundum, fearful of the impact this would have on the market for blue and yellow sapphires mined on the island. However, the heat treatment activities of Thai operators using the "geuda" have already placed the Sri Lankans in competition with themselves for these colored sapphires. A new gas oven from Japan that can be used with either a reducing flame /for blue sapphires) or an oxidizing flame (for rubies and yellow/orange sapphires) could encourage heat treatment of corundum in Sri Lanka.

Although heat treatment is virtually undetectable in some corundum, occasionally we see a stone that shows obvious signs of treatment. The New York laboratory recently examined an unusual sapphire cabochon that was approximately $90 \%$ colorless and had a thin band of dark blue color on its base (figure 1). The fact that the stone fluoresced chalky green in bands when exposed to short-wave ultraviolet radiation, and that the base exhibited "heat" craters with no "bleeding" (figure 2), indicates that the stone was heat treated rather than diffusion treated. Figure 2 also shows the even appearance of the color when viewed face up.

A 2.55-ct natural ruby of excellent color that was recently offered at

01984 Gemological Institute of America

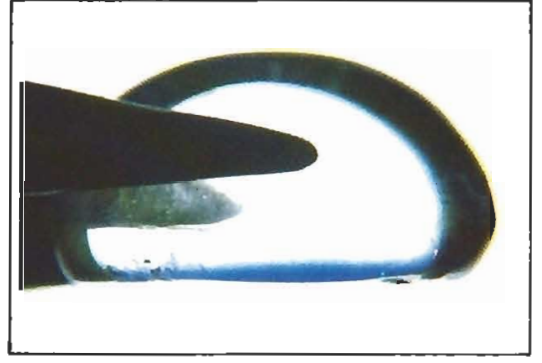

Figure 1. A thin band of blue on an otherwise colorless sapphire. Magnified $12 \times$.

auction also showed ummistakable signs of heat treatment. Unfortunately, the treatment caused severe internal fracturing, and one whole side of the pavilion (including the culet) had chipped away (figure 3). The stone looked pleasant enough table up, but could not stand scrutiny.

\section{“C-Ox," Another Trade Name for Cubic Zirconia}

The Los Angeles laboratory received for examination two colored stones that had been offered on the European market under the trade name "C-Ox." Figure 4 shows the deep green emerald-cut stone, which weighed approximately $4.14 \mathrm{ct}$, and the intense blue oval modified brilliant, which weighed approximately $3.73 \mathrm{ct}$. Both stones had a very high, almost metallic luster; both were singly refractive, and their refractive indices were above the limit of our standard duplex refractometer. The

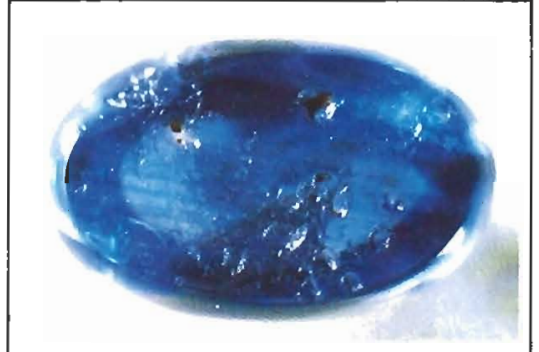

Figure 2. The craters in the base of the sapphire shown in figure 1 prove that this stone was heat treated rather than diffusion treated. Magnified $12 \times$.

specific gravity was determined by hydrostatic weighing to be 5.52 for the green stone and 5.34 for the blue stone. Both stones were inert to ultraviolet radiation. With the micro-

Figure 3. Note the internal fracturing and external chipping on this 2.55-ct ruby, caused by heat treatment. Magnified $16 \times$.

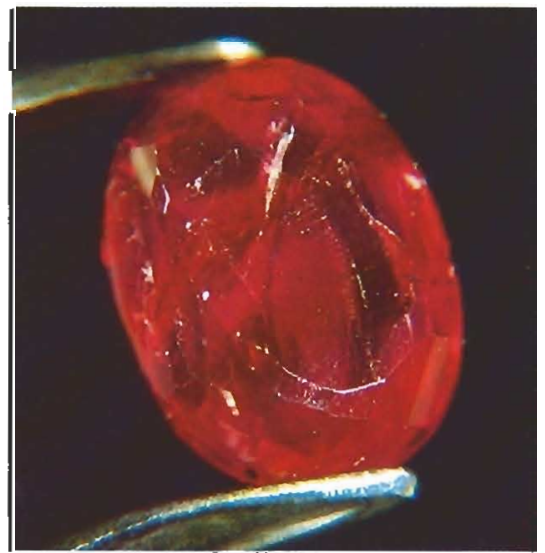




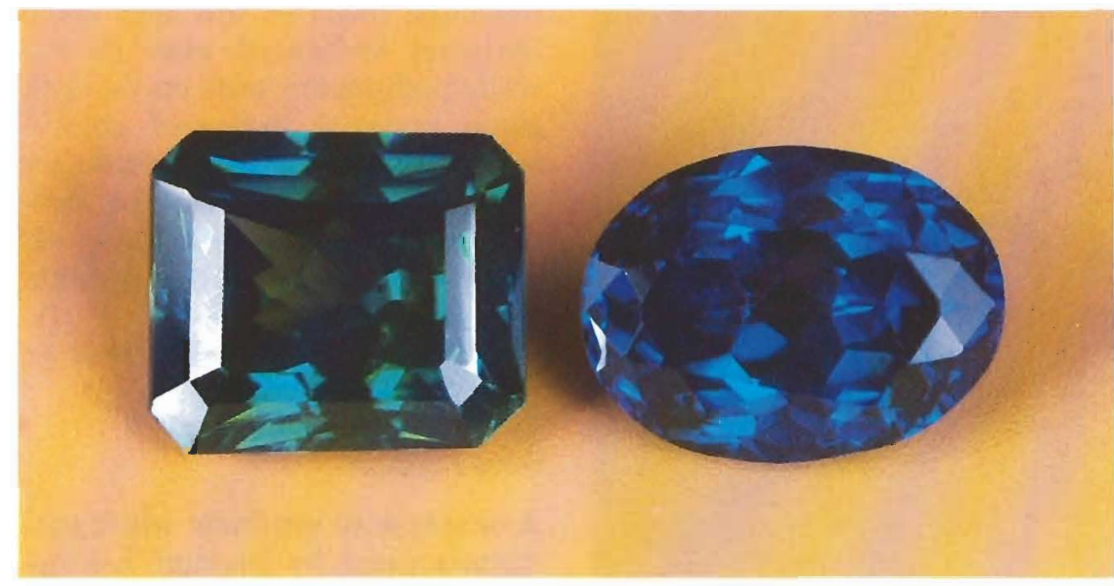

Figure 4. Green (4.14 ct) and blue (3.73 ct) cubic zirconia, marketed under the trade name " $\mathrm{C}-\mathrm{Ox}$."

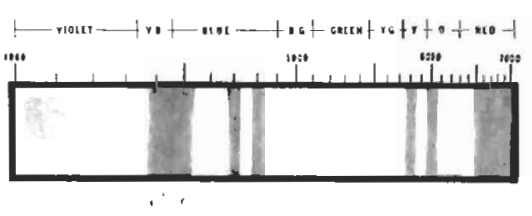

Figure 5. Absorption spectrum of the green " $\mathrm{C}$-Ox" illustrated in figure 4.

scope, no inclusions were visible in the blue stone, but the green stone showed a dense cloud of minute white inclusions that we could not identify. The absorption spectra of the stones were interesting. The blue stone showed a general absorption area around $5900 \AA$ and a cut-off area starting at $6500 \AA$ upwards. The green stone had a different absorption pattern: one broad, main absorption area was centered at $4450 \AA$, with narrower bands at 4700, 4800, 5800 , and $6000 \AA$ and a cut-off area from $6500 \AA$ up, as illustrated in figure 5. By means of X-ray diffraction, we were able to prove that both stones were synthetic cubic zirconia.

\section{DIAMOND}

\section{A Colored-Diamond Comet}

The New York laboratory recently examined the diamond brooch set sions in diamonds several times before (Gems \&) Gemology, Winter 1965-66, Fall 1966, Fall 1974, Fall 1979, and Spring 1980), we have never seen anything that equals the one in the approximately 4-ct stone pictured in figure 8 . Viewed from the pavilion, the major inclusion looks like a branching root system. However, because of its location within the diamond and the fact that the stone is pear shaped, the odd pattern is reflected throughout the entire stone ffigure 9).

\section{JADE Simulant}

A small ( $3 \mathrm{~cm}$ diameter), round ornament carved out of an opaque, yellowish brown, black, and grayish green material was submitted to the Santa Monica laboratory for identifi-

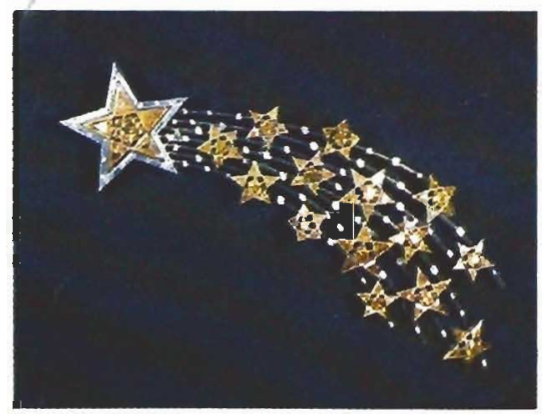

Figure 6. Comet-design

diamond brooch set with colored diamonds. Approximately $3 \frac{1}{2} 2$ in. $(9 \mathrm{~cm})$.

small colorless diamonds. The piece is unusual in that all of the stones, including the small colorless ones, are fluorescent, which suggests that whoever designed the piece and chose the stones had more than a passing interest in diamond fluorescence. Figure 7 shows the brooch as it appears when exposed to long-wave ultraviolet radiation.

\section{Dendritic Inclusions}

Although we at the New York lab have encountered dendritic inclu-

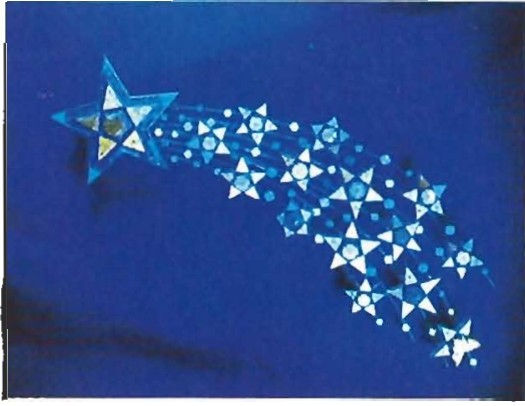

Figure 7. All of the stones in the brooch illustrated in figure 6 fluoresce when exposed to long-wave U.V. radiation.

Figure 8. Dendrites in diamond. Magnified $12 \times$.

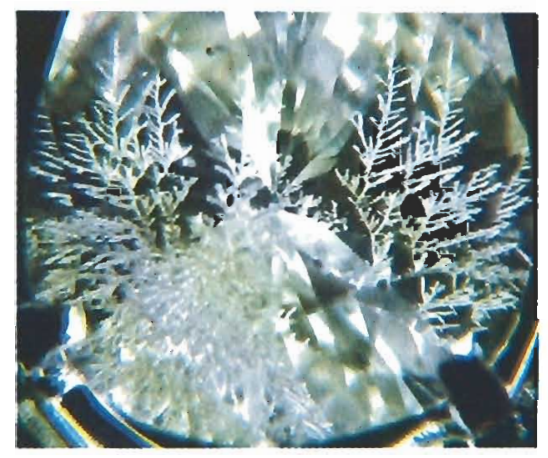




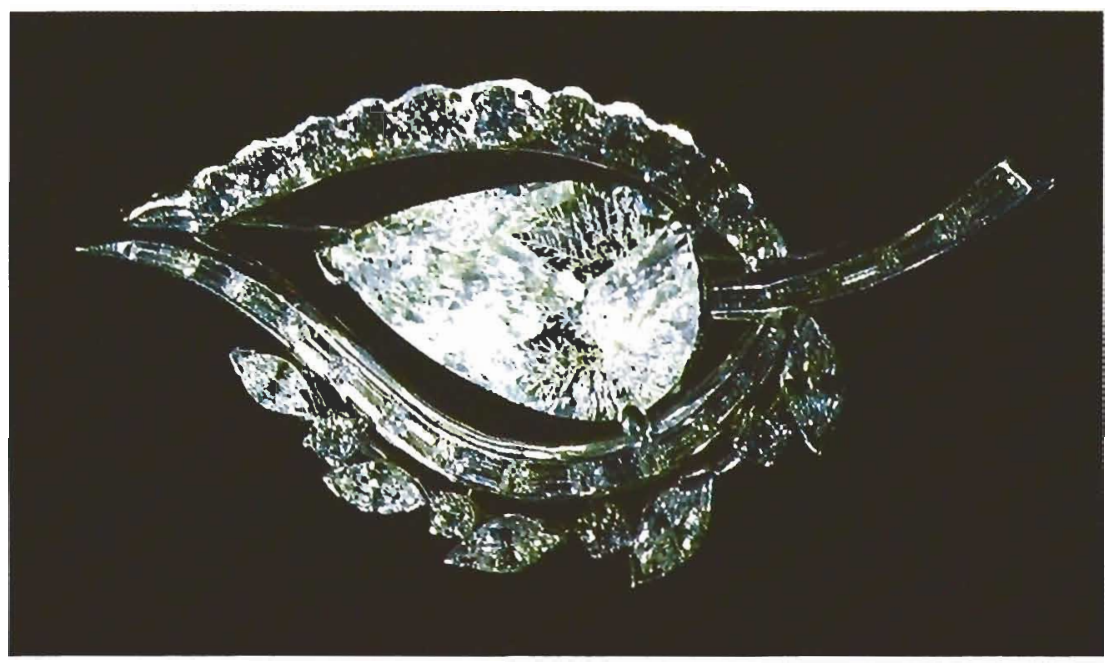

Figure 9. The pin containing the approximately 4-ct diamond illustrated in figure 8 with the dendrite pattern reflected throughout the stone.

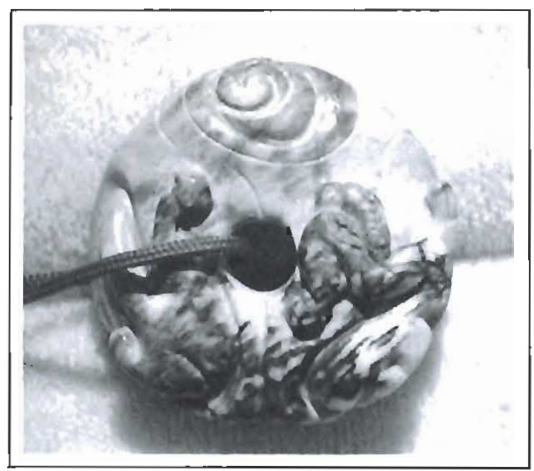

Figure 10. Ornament composed primarily of serpentine as a jade simulant.

cation (figure 10). The material was very soft and could be scratched with a pin. Although the polish was not good, we were able to obtain a vague refractive index reading of $1.57 \mathrm{in}$ some areas. The specific gravity was determined by hydrostatic weighing to be approximately 2.5 . There was a distinct yellow fluorescence to both long- and short-wave ultraviolet radiation. X-ray diffraction revealed patterns of forsterite and antigorite as well as additional lines that proved the material was a rock consisting of several minerals, but primarily serpentine. maw-sit-sit and chloromelanite. refractive index of the light green material indicated maw-sit-sit, while preliminary tests on the dark green material indicated chloromelanite. If additional tests are authorized and confirm these identifications, it would be the first example of this combination ever encountered in our lab.

\section{OPAL, A New Synthetic from Inamori}

A new type of synthetic white opal manufactured by Inamori has appeared on the American market. The Santa Monica laboratory had the opportunity to examine two $10 \times 12$ $\mathrm{mm}$ cabochons, each weighing approximately $2.80 \mathrm{ct}$ (figure 12 ). One cabochon has a milky white body color with predominantly green and blue play of color, while the other stone is more translucent, with a vivid play of color in red, orange, yellow, green, and blue. The refractive index was determined to be 1.46 (spot reading) for both stones, and the specific gravity for both was 2.20 . Examination with magnification did not reveal any distinctive inclusions in the more translucent stone; the

Figure 11. An eight-pound boulder that appears to consist of

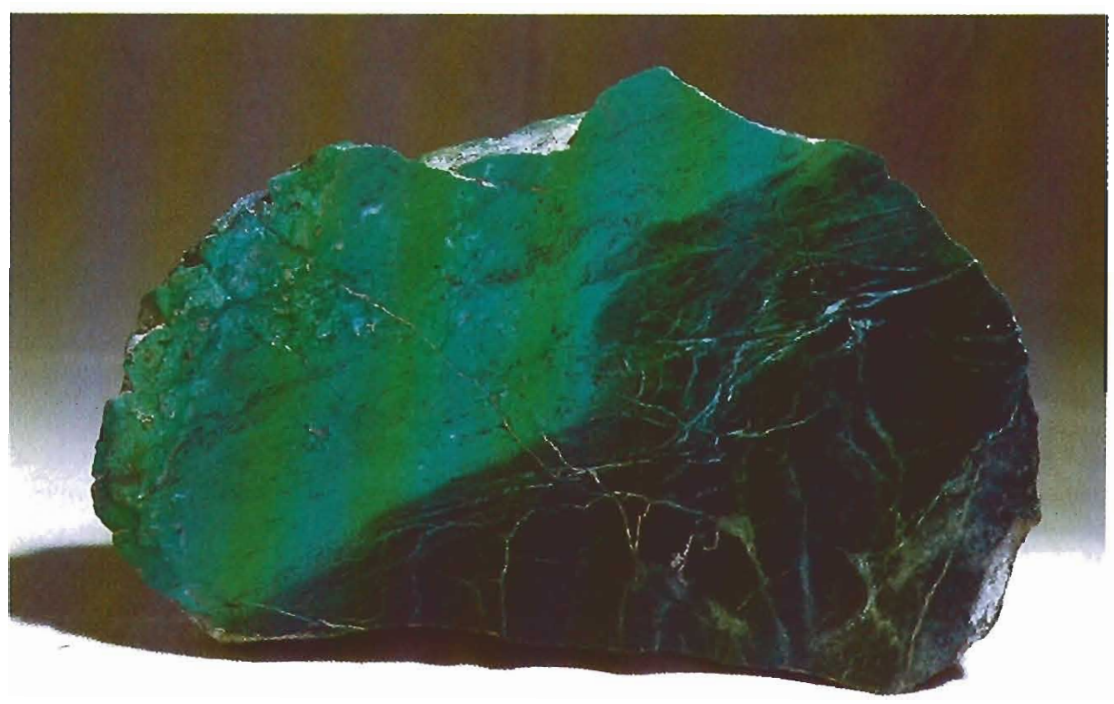




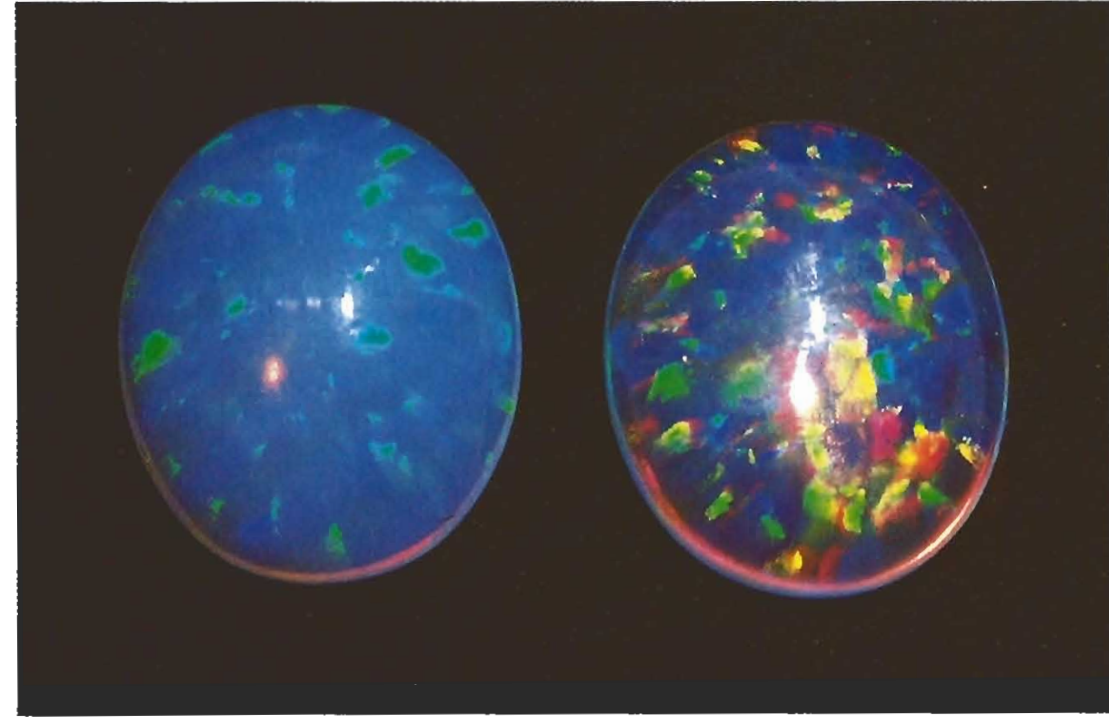

Figure 12. Two $10 \times 12 \mathrm{~mm}$ Inamori synthetic opals. (figure 13). The X-radiograph (figure 14) shows a considerable growth of nacre around the beads. The very thin layer of shell to which the beads were attached does not appear on the radiograph.

\section{Eroded Pearl}

A pearl importer thought our readers would be interested in seeing a badly damaged pearl that he had been asked to replace (figure 15). It was set in a ring with a typical claw mounting when he received it. After unmounting the pearl, he sent it to the Santa Monica laboratory to photograph the severe erosion at the points of contact of the prongs. We surmise that the person who wore this ring must have worn it a long time and had a very acidic skin condition, for milky white stone did show an opaque white, irregularly shaped inclusion that could not be identified.

When the stones were illuminated with overhead light, the lizard skin or chickenwire structure characteristic of synthetic opals, which was difficult to detect at first, became quite obvious. Finally, the two stones reacted differently to ultraviolet radiation. The milky white stone was completely inert, whereas the other stone showed a faint yellowish fluorescence, but only to short-wave ultraviolet radiation.

\section{PEARLS}

\section{Cultured 3/4 Blister Pearls}

In the Summer 1981 issue of Gems e Gemology (p. 104), we introduced cultured $3 / 4$ blister pearls. To date, all of the examples of this new type of pearl that we have seen have had a mother-of-pearl bead clearly exposed at the base. Recently, the New York lab X-rayed two $18-\mathrm{mm}$ cultured $3 / 4$ blister pearls in which the nuclei were not exposed. The pearls had been removed from the mollusc with shell attached. The nucleus of the smaller specimen was just visible-a white area underlying the thin shell

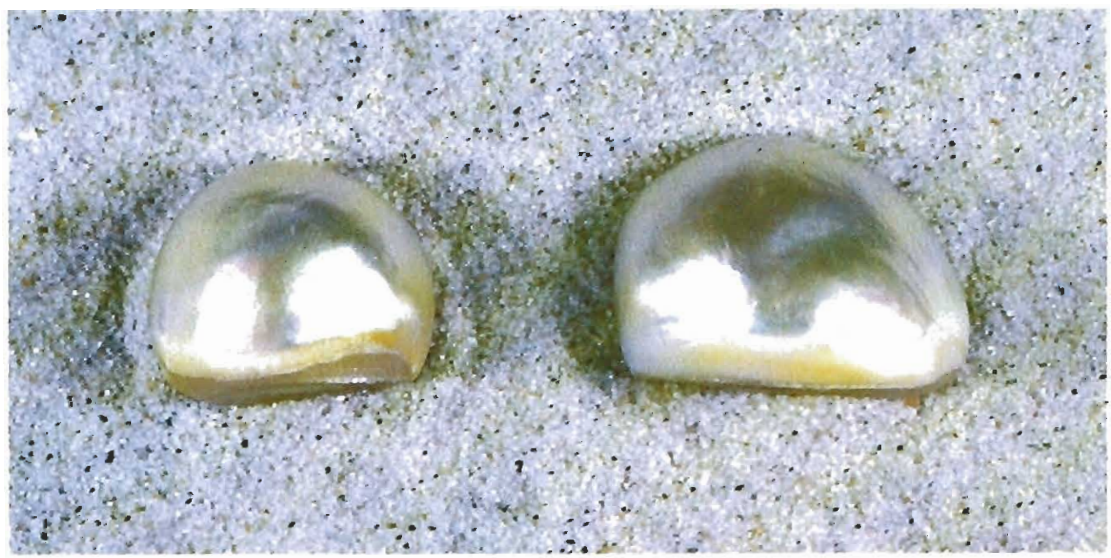

Figure 13. Cultured $3 / 4$ blister pearls without exposed nuclei. The largest is $21 \times 18 \mathrm{~mm}$.

Figure 15. Eroded $81 / 2-\mathrm{mm}$ pearl.

Figure 14. X-radiograph of the cultured $3 / 4$ blister pearls shown in figure 13 .
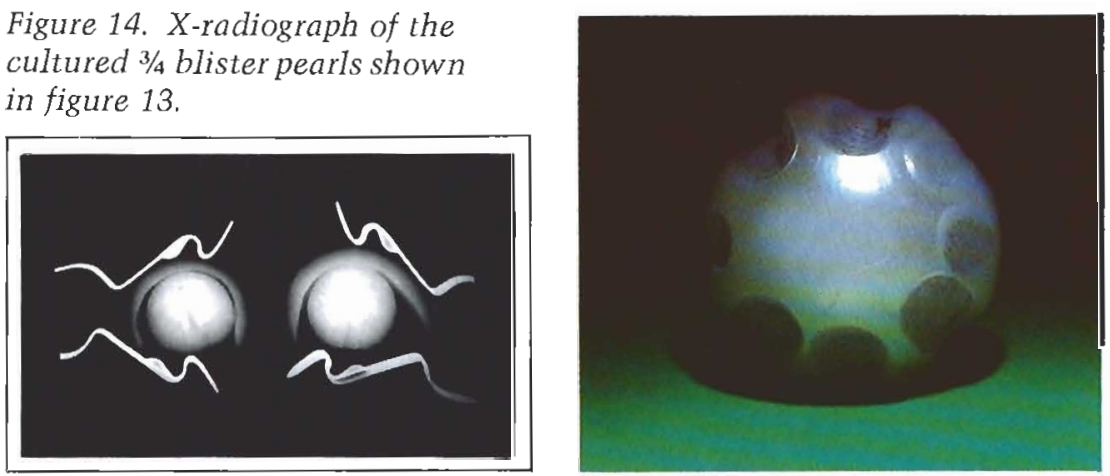
this is one of the worst examples of erosion we have ever seen.

\section{QUARTZ, Reddish Brown}

Submitted to the Los Angeles laboratory for identification was the 4.72-ct reddish brown oval modified brilliant shown in figure 16. The refractometer showed refractive indices of $\omega=1.540$ and $\epsilon=1.550$. When the stone was examined with the polariscope in conjunction with a condensing lens, a bull's-eye uniaxial interference figure was observed, thereby proving the stone to be quartz.

This color has been observed in some quartz from Rio Grande do Sul, Brazil, and is also reportedly produced by heat treating some amethyst to a temperature between $400^{\circ} \mathrm{C}$ and $500^{\circ} \mathrm{C}$.

Microscopic examination revealed only straight, parallel, and irregular growth and color zoning, which suggests that this stone is natural rather than synthetic. This color, however, could probably be produced in synthetic quartz, or by heat treating synthetic amethyst.

Figure 16. Reddish brown quartz, $4.72 \mathrm{ct}$.

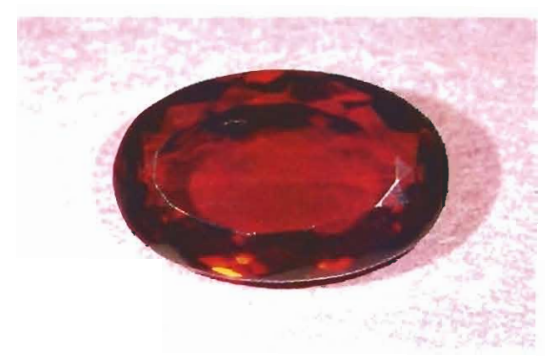

\section{RUBY, Early Verneuil Synthetic}

Figure 17, taken in New York, shows an unusually flawed 1.46-ct "Geneva Ruby." The tight curved striae that characterize this early type of Verneuil synthetic were easily seen in the stone with magnification. In addition to the striae and gas bubbles,

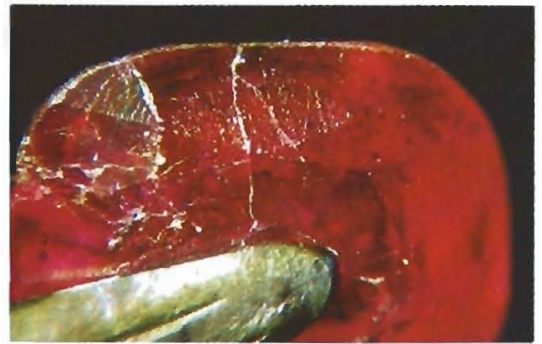

Figure 17. A 1.46-ct "Geneva (synthetic) Ruby," heavily flawed.

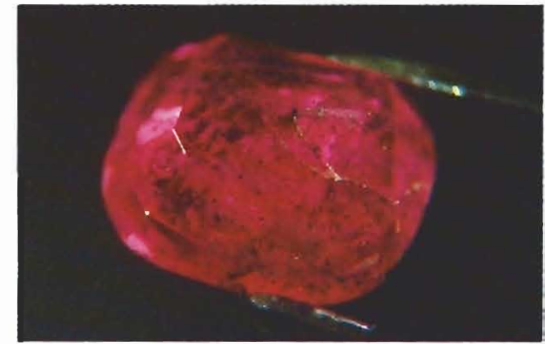

Figure 18. Note the dark inclusions in the "Geneva (synthetic) Ruby" illustrated in figure 17. Magnified $18 \times$.

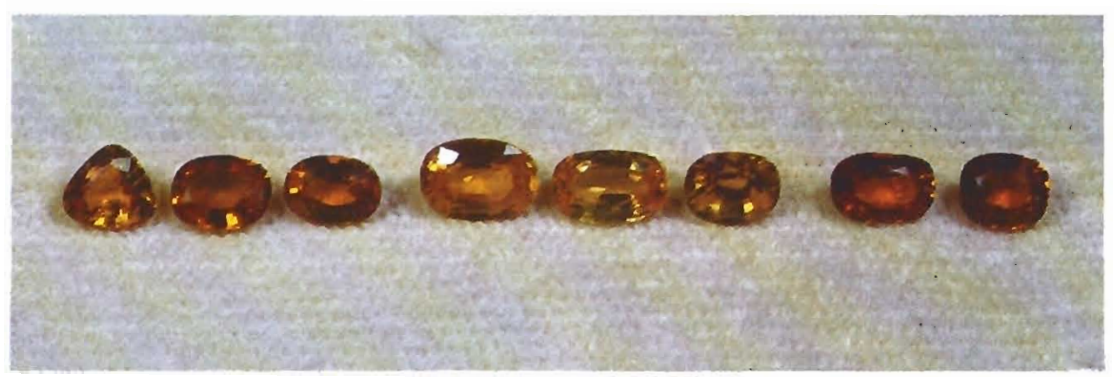

Figure 19. A range of colors found in heat-treated yellow sapphires.

Figure 20. "Colton-like" inclusions observed in heattreated yellow sapphires. Magnified $63 \times$.

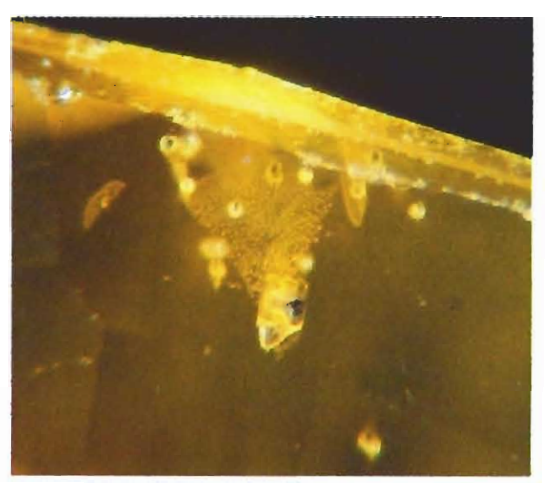

we observed a myriad of unidentified dark crystal-appearing inclusions (figure 18).

\section{YELLOW SAPPHIRES, Heat Treated}

Recently, the great majority of natu- ral yellow sapphires we have tested in New York owe their color to heat treatment. On rare occasions, we have seen an orange-brown iron-rich stone of natural color, but more frequently the naturally colored stones are pale yellow with strong orange fluorescence. Figure 19 illustrates a range of colors produced by heat treatment; the stones are all from the same batch heated in Thailand. Figure 20 shows some peculiar "cottonlike" inclusions around the crystal inclusions seen in one of the lightercolored stones. The "cotton" may represent partial absorption of the crystal inclusions because of heat.

Figure 21 shows a group of natural sapphires that reportedly had been locked in a safe for decades. It was a pleasure to be able to report that the stones were not only natural sapphires but also natural in color, although they were quite well worn. The square, lighter-colored stone is a typically orange-fluorescing Sri Lankan stone. The oval stone next to 


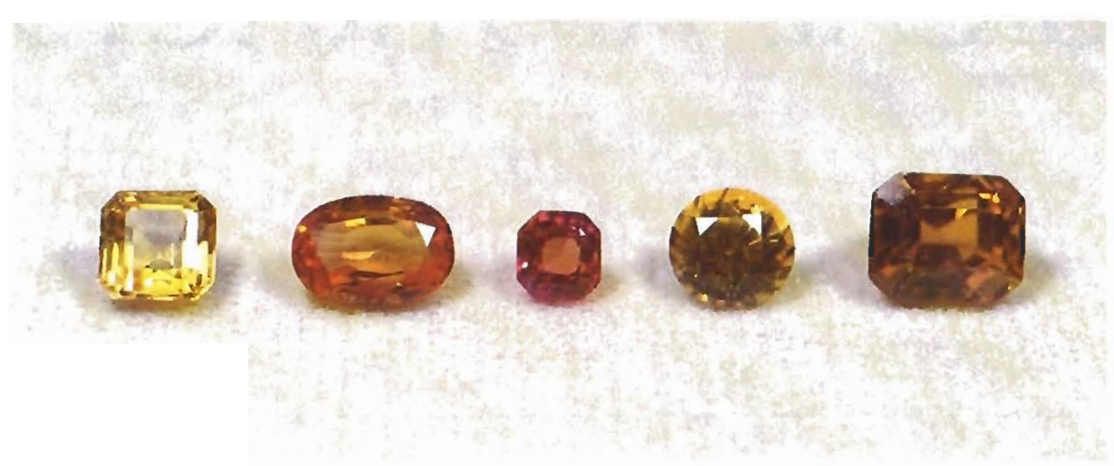

Figure 21. A group of naturally colored yellow sapphires. The largest is approximately $4 \mathrm{ct}$.

it is also a typical Sri Lankan stone, with a chromium line in the absorption spectrum. The small orangepink stone was nearly flawless, but proved to be natural. The round stone again had all the characteristics of a darker than usual Sri Lankan stone, while the dark stone showed an iron absorption spectrum typical of natural yellow-brown Thai sapphires.

\section{ZIRCON, A Rare \\ Cat's-Eye}

The Santa Monica laboratory re- ceived for identification a grayish green 3.43-ct oval cat's-eye cabochon that had been purchased as cat's-eye zircon. The stone was easily identified as zircon because it showed the diagnostic absorption spectrum with the most prominent line at $6535 \AA$. Microscopic examination revealed long, thin, needle-like inclusions of unknown composition running across the stone, thus causing the chatoyancy. Figure 22 shows the quite attractive cabochon. Although cat's-eye zircon does not-according to the gemological literature-occur often, our New York laboratory had previously mentioned this type of

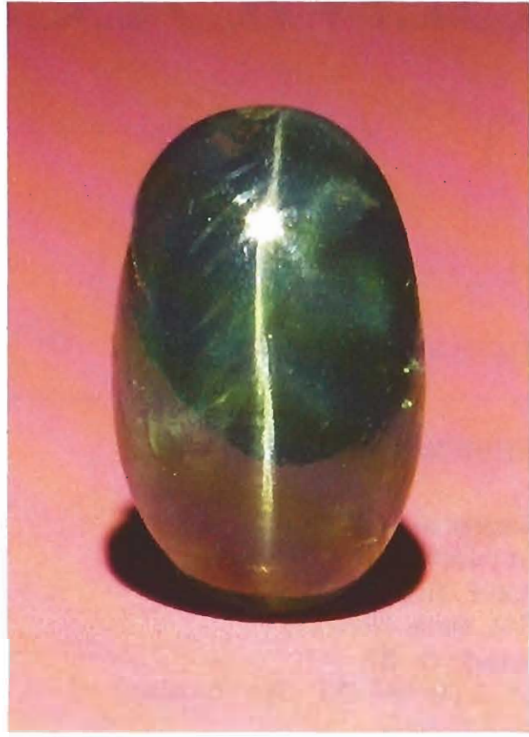

Figure 22. A 3.43-ct cat's-eye zircon.

cat's-eye in the Summer 1974 issue of Gems et) Gemology.

\section{ACKNOWLEDGMENTS}

Andrew Quinlan from New York supplied figures $1,2,3,6,7,8,9,11,13,14,17,18$, 19,20 , and 21. Shane McClure provided figure 16. Figure 22 was supplied by Tino Hammid, and Karin Hurwit was responsible forfigures 5 and 10. Mike Havstadsupplied figures 4, 12, and 15. 